\title{
RELATO DE EXPERIÊNCIA: RODA DE TERERÉ PARA ADOLESCENTES NA UNIDADE BÁSICA DE SAÚDE (UBS) - VILA VIEIRA
}

\author{
EXPERIENCE REPORT: TERERÉ CIRCLE FOR TEENAGER IN THE \\ BASIC HEALTH UNIT (BHU) - VILA VIEIRA
}

\author{
Lavínia dos Santos Chagas ${ }^{1}$ \\ Rayssa Kelly de Souza Chaves ${ }^{1}$ \\ Thais Nunes Mendonça ${ }^{1}$ \\ Nicole Guedes Maia ${ }^{1}$ \\ Laryssa Yanel Escobar Cañete ${ }^{1}$ \\ Ana Paula Dossi de Guimarães e Queiroz ${ }^{1}$
}

Resumo: A atenção primária à saúde tem como estratégia prioritária a Saúde da Família, que busca promover a qualidade de vida da população brasileira e intervir em fatores determinantes da saúde. Considera-se esta como um todo e não somente a ausência de doenças. Com o objetivo de contribuir para o maior alcance possível da população adscrita e dessa forma, obter melhores resultados, a disciplina Atenção à Saúde da Comunidade, permitiu o aporte dos acadêmicos do $2^{\circ}$ ano do curso de medicina da Universidade Federal da Grande Dourados (UFGD), para a realização de visitas domiciliares na região de uma Unidade Básica de Saúde (UBS) pré-determinada e concluir com uma intervenção. Este relato discorre sobre a intervenção executada na UBS Vila Vieira da cidade de Dourados - MS, que se consistiu em uma roda de conversa direcionada para jovens da região com a intenção de abordar temas do cotidiano dessa faixa etária, como saúde emocional, sexualidade e doenças sexualmente transmissíveis. Tal ação teve como foco principal sanar as dúvidas concernentes às temáticas citadas, a fim de informar e contribuir para a promoção de saúde dessa faixa etária.

Palavras-chave: Saúde da comunidade, Atenção primária à Saúde, Adolescentes, Educação Médica.

Abstract: Primary health care has as its priority strategy the Family Health, which seeks to promote Brazilian population's quality of life and to intervene in determinants of health. It is considered in all its aspects. Then, this is not only an absence of disease. With the objective of contributing as much as it's possible reach of the population enrolled and thus, to obtain better results, the discipline Community Health Care, allowed the contribution of the second year students from Medical School of the Federal University of Grande Dourados (UFGD), to carry out home visits in the region of a predetermined Basic Health Unit (BHU) and to conclude this with an intervention. This 
report discuss the intervention carried out at UBS Vila Vieira in the city of Dourados MS, which consisted of a talk group aimed at young people from that region, with the intention of approaching daily topics about this age group, such as mental health, sexually and sexually transmitted diseases. The main focus of this action was to address doubts concerning the themes mentioned, in order to inform and contribute to health promotion of this age group.

Keywords: Community health, Primary health care, Teenager; Medical Education.

\section{INTRODUÇÃO}

A adolescência é um período de transição em que as características físicas, psíquicas e sociais do indivíduo passam por um processo de profunda transformação. Segundo o Fundo das Nações Unidas para a Infância (UNICEF), em 2016, havia 1,2 bilhões de adolescentes na faixa etária de 10 a 19 anos, o que representa cerca de 16\% da população mundial. Apesar desse número significativo, a subdiretora-geral assistente da Organização Mundial de Saúde (OMS) alega que os adolescentes estão totalmente ausentes dos planos nacionais de saúde há décadas. Tal grupo é vulnerável aos agravos sociais, por isso, a proteção e a promoção da saúde do adolescente é algo que requer empenho, uma vez que se trata de indivíduos que não amadureceram a ponto de conseguirem lidar com as pressões impostas pela sociedade sem a ajuda de alguém.

No Brasil, apesar de ter mais de 21 milhões de adolescentes, segundo a UNICEF, não há muitas ações e serviços voltados para esse grupo. Um exemplo foi o estudo realizado em 51 Unidades Básicas de Saúde na cidade de Londrina- PR, onde se percebeu que cerca de 97\% dos médicos e enfermeiros das equipes da Saúde da Família referem a não existência, no serviço de atenção básica de saúde do município, de um programa específico para os adolescentes (FERRARI, et al., 2008). Um dos motivos é a falta de prioridade para essa faixa etária, devido à alta demanda de outros problemas nas UBSs (FERRARI, et al., 2006). Outra explicação é a necessidade de adequação da linguagem e da forma de atuação dos profissionais, para o alcance de um nível de compreensão dos vários segmentos que constituem esta população (RUZANY, 2008).

Os adolescentes estabelecem um grande desafio para a estruturação da integralidade na Atenção Primária à Saúde (APS). Isso ocorre porque há uma apreensão e resposta complexa ao conjunto de suas demandas de saúde, as quais decorrem tanto do 
processo de crescimento, quanto do desenvolvimento, próprio dessa faixa etária, mas, sobretudo, dos aspectos socioculturais relacionados (AYRES, et al., 2012).

Além do mais, há assuntos relacionados à saúde pública que acometem preferencialmente esse grupo, os quais estão envolvidos, em sua maioria, em questões ligadas à sexualidade, gravidez na adolescência, uso de métodos contraceptivos, doenças sexualmente transmissíveis (DST's) e as mudanças do corpo nesse período. Esses são assuntos pouco esclarecidos para a maioria dos adolescentes devido ao tabu que os envolve, no entanto, apesar da necessidade que o adolescente tem de um acompanhamento com um profissional da área da saúde, eles consultam menos ao médico do que qualquer outro grupo etário (COSTA; BIGRAS, 2007).

Sabe-se também que o confronto entre as necessidades de saúde trazidas pelos adolescentes e as ações oferecidas poderá revelar as mudanças no modelo assistencial. Tais transformações são potenciais construtoras de vínculo, aproximando quem oferece ou presta o serviço de quem o recebe (DOS SANTOS; RESSEL, 2013). Por esse motivo, notou-se a necessidade de um projeto que atraia os adolescentes para a UBS, além de criar um contato com os profissionais de saúde.

O objetivo desse texto é relatar o trabalho dos estudantes de medicina do terceiro período da UFGD realizado na UBS Vila Vieira, em Dourados, Mato Grosso do Sul (MS), com o intuito de realizar um projeto voltado para os adolescentes, abordando alguns assuntos importantes dessa faixa etária, além de aproximar os profissionais de saúde com os jovens da região e mostrar os serviços que a UBS pode ofertar para esse grupo, já que muitas vezes, eles são desconhecidos. Dessa forma, tudo isso, foi concretizado, por meio de uma roda de tereré, que atraiu os jovens para que esse propósito fosse alcançado.

\section{METODOLOGIA}

Os alunos do terceiro semestre de Medicina da UFGD, na disciplina de Atenção à Saúde da Comunidade, foram divididos em oito grupos e cada um deles acompanhou a rotina de determinadas unidades básicas de saúde. O objetivo dessa atividade foi reconhecer a realidade de cada território, por meio de visitas domiciliares, junto com os agentes de saúde e, a partir disso, realizar um projeto que promova uma ação de saúde a fim de colaborar mais com a comunidade local. 
Nesse relato de experiência, foi visitado a UBS, ESF Elis Reny dos Santos, localizado no bairro Vila Vieira, como é popularmente conhecida. No período do estágio realizado foi observado um elevado número de idosos, principalmente aqueles com doenças crônicas como hipertensão e diabetes. Porém, constatou-se que a UBS e a comunidade possuem várias atividades que atendem a esse grupo. Como exemplo, pode-se citar o Hiperdia, um dia da semana destinado aos portadores de hipertensão e diabetes. Além do mais, no bairro há atividades de lazer para esses idosos, como os bailes voltados para a terceira idade. Notou-se, também, que não havia nenhuma atividade voltada para os adolescentes da região, o que configurou um escasso contato com esse grupo por parte dos próprios agentes da saúde. Inclusive, muitos deles não sabem como lidar com essa faixa etária. Devido a isso, escolheu-se trabalhar com os jovens da população adscrita e abordar algumas temáticas de saúde que estão relacionadas a essa idade. A intervenção se deu por meio de uma roda de tereré ${ }^{\text {no }}$ período vespertino, um tipo de lazer comum para os moradores da região de Dourados.

A divulgação desse projeto foi realizada por meio de convites impressos (Figura 1), os quais foram entregues aos jovens do bairro pelos agentes de saúde quatro dias antes da intervenção. Além disso, dois dias anteriores ao evento, divulgou-se a roda de tereré, no período matutino, em duas escolas, onde a maioria desses adolescentes estuda A primeira a ser visitada foi o Escola Rosa Câmara, o qual está na região adscrita da UBS e, neste local, foram convidados apenas os alunos do nono ano, pois essa turma era a única que correspondia à faixa etária escolhida (de 14 a 18). A fim de se criar um contato inicial com esse público alvo, foi feita uma palestra informal sobre a dengue, na qual as acadêmicas lhes ensinaram como fazer um repelente natural, pois essa doença possui alta taxa de incidência no bairro (Figura 2). A segunda foi a Escola Estadual Professora Floriana Lopes, na qual se realizou apenas o convite aos alunos do ensino médio, já que nela há também alunos de outras regiões. Considerando que esse é um público difícil de ser atraído, e que muitos deles trabalham durante o período vespertino, foram convidados cerca de 200 jovens, com o intuito de ao menos $10 \%$ comparecesse à roda de conversa.

1 Bebida típica de alguns países da América do Sul e da região centro-oeste do Brasil. É feita da infusão da erva-mate em água fria. 


\section{REALIZZAÇẬO}

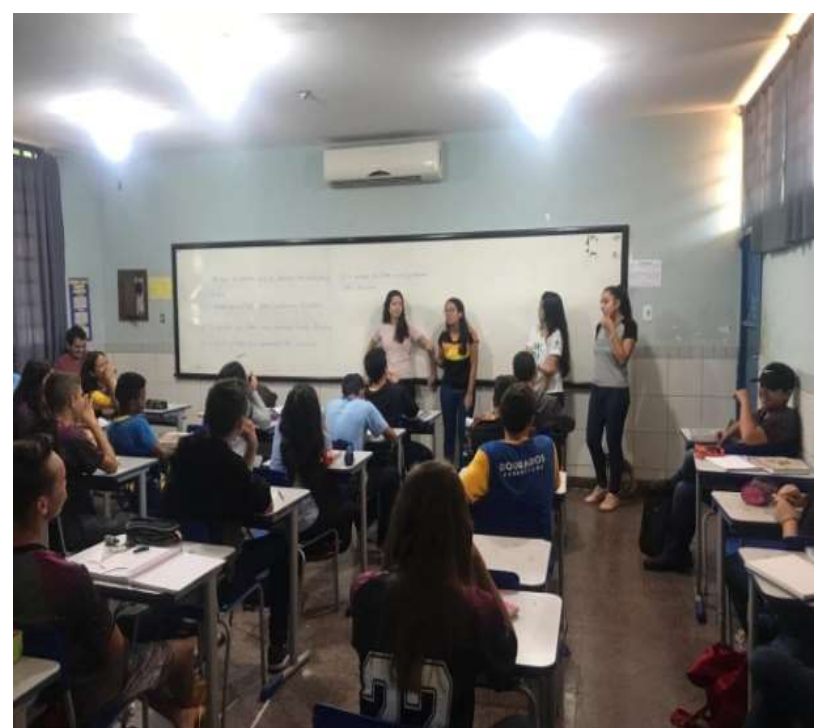

Figura 1: Convite sendo realizado aos alunos do nono ano da Escola Rosa Câmera, juntamente com uma palestra informal sobre a dengue.

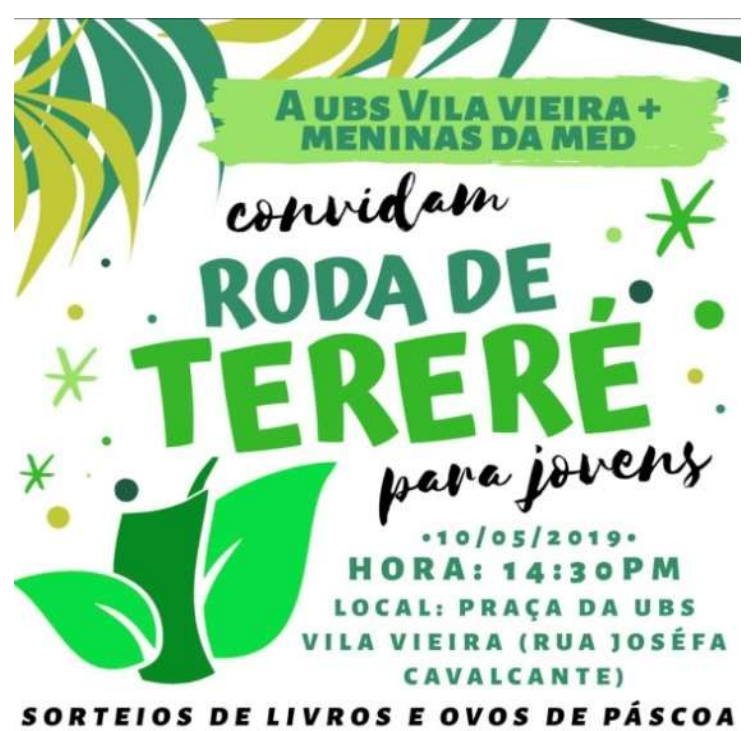

Figura 2: Convite entregue para os adolescentes do bairro Vila Vieira.

Ademais, sabendo desses empecilhos, decidiu-se fazer sorteios de ovos de páscoas e livros didáticos para motivar ainda mais a presença desses indivíduos na roda. Vale ressaltar que, horas antes da intervenção, o convite foi reforçado via aplicativo de mensagem para o líder da sala, o qual ficou responsável por reencaminhar aos colegas de classe.

\section{RESULTADOS E DISCUSSÃO}

Concluída a primeira fase do projeto, o convite, teve-se, como local de realização da segunda parte, a praça ao lado da UBS, no período da tarde, durante o funcionamento da unidade. A roda durou duas horas e quinze minutos, com início efetivo às $14 \mathrm{~h} 45 \mathrm{~min}$ e finalização às $17 \mathrm{~h}$. Além dos 15 adolescentes que estiveram presentes, a roda de tereré contou ainda com quatro agentes comunitários de saúde, um enfermeiro e o médico da unidade. A psicóloga, a educadora física e a fisioterapeuta da equipe do Núcleo de Apoio à Saúde da Família (Nasf) também estiveram presentes.

Com o intuito de se estabelecer uma relação de proximidade com os adolescentes, estruturalmente, a roda se constituiu de maneira informal, de modo que os participantes se sentaram em círculo, sobre forros estendidos na grama. Além das 
bombas de tereré, erva, água que foram levadas pelas acadêmicas e também pelos próprios indivíduos, serviu-se pipoca durante a realização do bate papo (Figura 3).

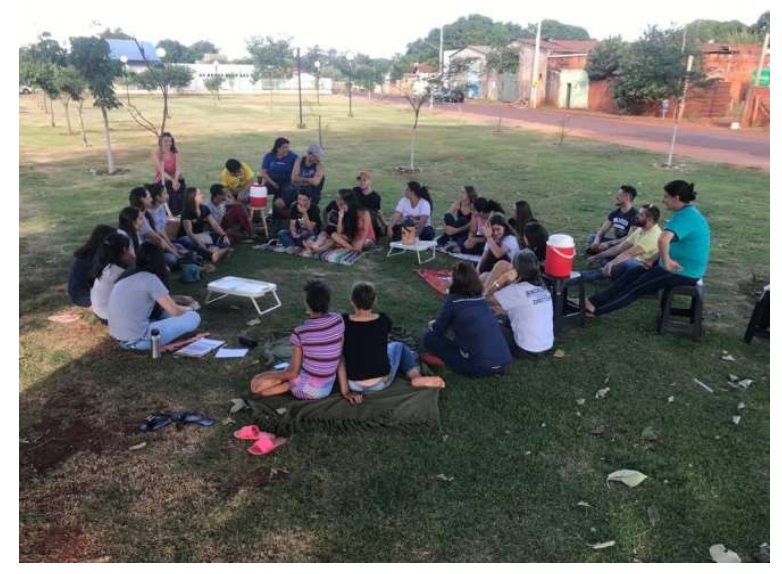

Figura 3: Roda de tereré

Houve duas rodas de conversa, nas quais as discentes do terceiro período abordaram distintos temas com enfoque na realidade vivida por essa faixa etária selecionada. Iniciou-se com uma dinâmica quebra-gelo, pela educadora física, para que os adolescentes pudessem se sentir mais à vontade. Posteriormente, introduziu-se a discussão sobre bullying e ciberbullying, por duas acadêmicas, foi perceptível o interesse dos participantes, seguiu-se então, com a dinâmica que tinha o intuito de identificar quem já sofreu dessa problemática social. Percebeu-se, assim, que a maioria já havia sido vítima de bullying e devido a isso, evidenciou-se a presença de tais atos no cotidiano das escolas e que, em virtude das consequências que essas ações acarretam, deve-se combatê-las de modo incisivo. Entre as conversas, foram realizadas mais duas dinâmicas, nas quais participaram todos os que estavam presentes. A primeira teve objetivo de se fomentar o trabalho em grupo, ao passo que a segunda trabalhou as diferenças existentes entre os indivíduos para que estes pudessem observar que, apesar da faixa etária similar, eles possuíam vivências e características psicossociais distintas. No seguinte diálogo, tratou-se de assuntos como a sexualidade, DSTs e gravidez precoce, visto que são temáticas que afetam em demasia esse grupo de indivíduos.

Vale frisar que durante as ministrações, tanto os profissionais da saúde quanto os próprios adolescentes compartilharam opiniões e experiências sobre as temáticas discutidas, o que conferiu dinamicidade e ampliação de informações. Posterior a isso, abriu-se um momento para dúvidas, em que foram entregues papéis e canetas para os 
integrantes da roda, para que as perguntas fossem anônimas, evitando, desse modo, qualquer tipo de constrangimento aos adolescentes. $\mathrm{O}$ médico da unidade ficou responsável por sanar as dúvidas, além de acrescentar informações a respeito das DSTs de uma forma mais didática, ensinando sobre o uso das camisinhas masculina e feminina, explanou sobre os recursos que a UBS fornece, o que contribuiu para qualificar a roda de tereré como um veículo que possibilitou a apresentação dessa unidade, bem como todos os serviços ofertados. Ao final, para o encerramento do projeto, realizaram-se sorteios de livros didáticos do ensino médio e ovos de páscoa.

\section{CONSIDERAÇÕES FINAIS}

Com base na experiência vivenciada na roda de tereré para adolescentes, fica explícita a importância de tal ação para a comunidade, principalmente no que concerne a essa faixa etária, pois, geralmente, não há ações e projetos para esse público ao se tratar de temas relacionados à saúde emocional, física, com foco na prevenção de doenças e promoção de saúde. Salienta-se que esse grupo tem papel fundamental de propagação de informações pela capacidade cognitiva para aprender, reproduzir e influenciar as demais pessoas ao redor.

É relevante ressaltar o quão construtivo e agregador foi a experiência supracitada para a formação acadêmica e pessoal na vida das autoras. Além disso, situações vividas na Unidade Básica de Saúde serão lembradas de forma gratificante por terem sido o primeiro contato com o SUS, usuários e funcionários do sistema.

Para agregar valor ao projeto e este apresentar melhores resultados, é necessário que haja um olhar detalhado na escolha do local, pois barulhos externos de alta intensidade podem dispersar os participantes e atrapalhar a comunicação em momentos pontuais. Ademais, o horário deve ser observado para que haja maior período de tempo na resposta de possíveis dúvidas dos integrantes da roda de conversa. Outro aspecto importante que pode ser ressaltado é a necessidade de se abordar os temas da forma mais didática possível. Isso porque houve falta de atenção de alguns jovens em um momento específico, no qual se usou termos técnicos e dados epidemiológicos importantes para demonstrar a prática e prevalência de patologias, nesse caso, das doenças sexualmente transmissíveis.

Sem mais fatores a serem alterados, conclui-se que tal projeto teve uma excelente execução e houve uma repercussão assertiva, tanto entre os funcionários e servidores da UBS quanto na comunidade. De modo geral, o feedback foi extremamente 
positivo e, por esse motivo, há afirmações de que terá a continuidade dessa ação de educação em saúde com mesmo nome e configuração. Existiu ainda a incitação por parte dos funcionários de que a "Roda de tereré para adolescentes" seja um projeto de extensão e de que se perpetue.

A fala do enfermeiro: “[...] não dá pra parar por aí, é algo que dá pra passar pra frente. Vocês vão seguir a vida, mas o projeto continua", foi marcante, e o incitamento da Coordenadora da UBS, para que as acadêmicas "sejam essas futuras médicas que a saúde pública do Brasil e as unidades de saúde necessitam”, selou o sentimento de missão cumprida com extrema felicidade de saber que o projeto criado e desempenhado pelas autoras foi um sucesso.

\section{REFERÊNCIAS BIBLIOGRÁFICAS}

AYRES, J.R.C.M. et al. Caminhos da integralidade: adolescentes e jovens na Atenção Primária à Saúde. Interface-Comunicação, Saúde, Educação, v. 16, n. 40, p. 67-82, 2012.

COSTA, M.C.O.; BIGRAS, M. Mecanismos pessoais e coletivos de proteção e promoção da qualidade de vida para a infância e adolescência. Ciência \& Saúde Coletiva, v. 12, p. 1101-1109, 2007.

DOS SANTOS, C.C; RESSEL, L.B. O adolescente no serviço de saúde. Adolescência e Saúde, v. 10, n. 1, p. 53-55, 2013.

FERRARI, R.A.P; THOMSON, Z.; MELCHIOR, R. Adolescência: ações e percepção dos médicos e enfermeiros do Programa Saúde da Família. Interface-Comunicação, Saúde, Educação, v. 12, p. 387-400, 2008.

FERRARI, R.A.P; THOMSON, Z.; MELCHIOR, R. Atenção à saúde dos adolescentes: percepção dos médicos e enfermeiros das equipes da saúde da família. Cadernos de saúde pública, v. 22, p. 2491-2495, 2006.

RUZANY, M.H. Atenção à saúde do adolescente: mudança de paradigma. Saúde do Adolescente, 2008. 